\title{
Primary and secondary prevention trials in coronary heart disease
}

\author{
A. G. SHAPER* \\ F.R.C.P., F.R.C.Path., F.F.C.M. \\ MRC Social Medicine Unit, London School of Hygiene and Tropical Medicine, \\ London WCIE 7 HT
}

\begin{abstract}
Summary
Trials in primary and secondary prevention of coronary heart disease (CHD) are reviewed. The results of completed primary prevention trials suggest that dietary changes in middle-aged men may lower the incidence of CHD. Multifactorial trials may achieve an even greater reduction in CHD. Secondary prevention trials indicate that stopping smoking and the use of betablocking agents are effective in reducing recurrence rates.
\end{abstract}

\section{Introduction}

The arguments for a preventive approach to coronary heart disease (CHD) arise from the present size of the problem and its changing age pattern, from the realization that medical or surgical intervention is unlikely to affect the overall mortality and from the nature of the underlying disease process. In this presentation, the size and nature of the coronary heart disease problem in the U.K. and the present status of prevention trials in general will briefly be examined. We will then try to assess what more can be done in both primary and secondary prevention. Fundamental to the preventive approach is the belief that CHD is not an inevitable consequence of ageing or affluence and that its impact on our society can be considerably diminished.

CHD as a cause of death in the U.K.

If we examine the causes of death in men aged 45-54 years of age in England and Wales, we see that $51 \%$ of male deaths are cardiovascular (CVD); three-quarters of these are due to CHD. By comparison, cancer $(27 \%)$ and accidents $(7 \%)$ contribute considerably less to total mortality. Even in the 35-44 year age group, CVD accounts for $41 \%$ of all male deaths and again, three-quarters of these are due to coronary heart disease (Fig. 1). Within the U.K. there are such marked regional differences that, in assessing the size of the problem, we must consider England and Wales, Scotland and Northern Ireland as separate entities, at least from a CHD point of view.

* Present address: Professor A. G. Shaper, Department of Clinical Epidemiology, 21 Pond Street, London NW3 2PN.
Figure 2 shows the annual death rates for CHD in men at three age levels (35-44, 45-54 and 55-64 years) and at three periods in time (1950, 1960 and 1970). In all three age groups and for each time period Scottish death rates exceed those obtaining in England and Wales; rates in Northern Ireland are intermediate. In all age groups the English and Welsh show a steady increase in rates over the 20 years; the Scottish pattern is similar, although in the older age group it seems to have remained steady over the past decade, but steady at a very high level.

Some figures from a recent report on CHD illustrate the changing pattern of the disease in the U.K. in greater detail (DHSS, 1974). In England/Wales the younger men (35-44) have shown a $100 \%$ increase from 1950 to 1966 and still remain at a rate veryc. much higher than 1950 (Fig. 3). The two older age? groups show a $50 \%$ and $25 \%$ increase respectively, which is just as well for total mortality, bearing in mind the rates at these ages. Scottish men have shown a $75 \%$ increase in the younger age group, but as their rate is already much higher than the English/ Welsh rate, this lower rate of increase must be very cold comfort to the Scots.

\section{The community view}

Studies from Oxford, Edinburgh and London of myocardial infarction and sudden death in defined communities make it possible for us to see CHD as it really is, and not as it appears from the hospital or the coronary care unit (Kinlen, 1969; Armstrong et al., 1972; Pedoe, 1975). In these three community studies, nearly two-thirds of fatal attacks were medically unattended. Most deaths occurred at the place of onset of symptoms, usually home or at work, and only one-third took place in hospital. The majority of coronary deaths occurring within 28 days of the onset of the attack take place within $1 \mathrm{hr}$ and most of these at the beginning of that hour.

Coronary care units can only save the lives of those patients surviving long enough to reach their facilities. In an attack, the majority of deaths are too sudden for present medical intervention and the overall effect of coronary care units is too small to 

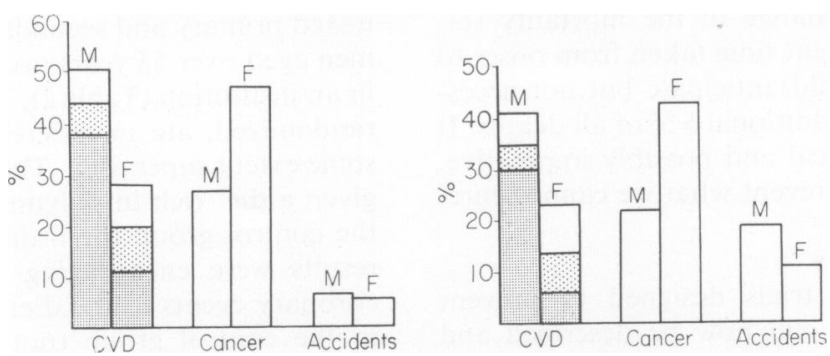

FIG. 1. Causes of death (percentage) in men aged 45-54 and 35-44 years in England and Wales in 1971.

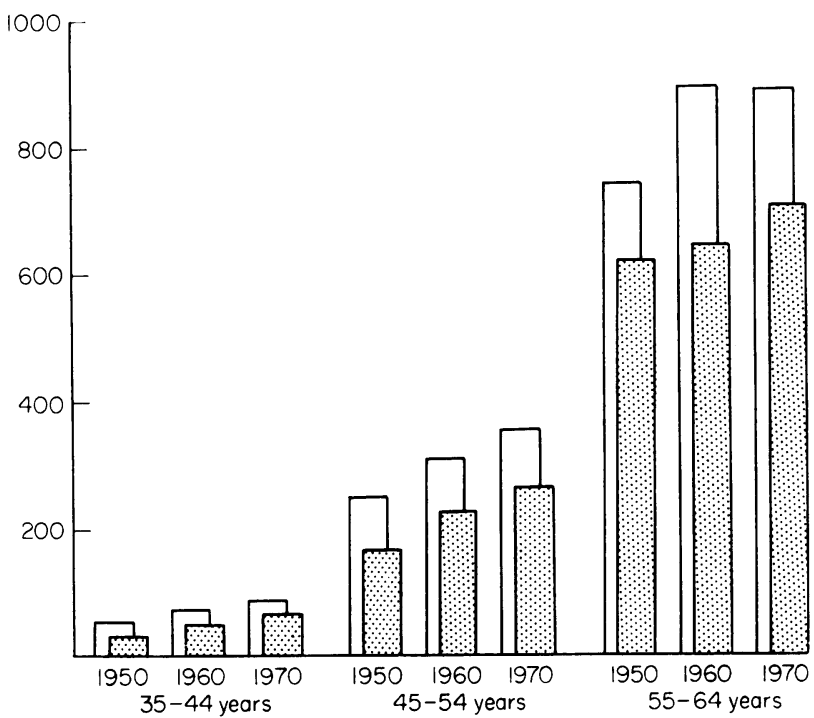

Fig. 2. Annual death rate per 100,000 from ischaemic heart disease for males in England and Wales (疄) and Scotland ( $\square$ ) (DHSS, 1974).

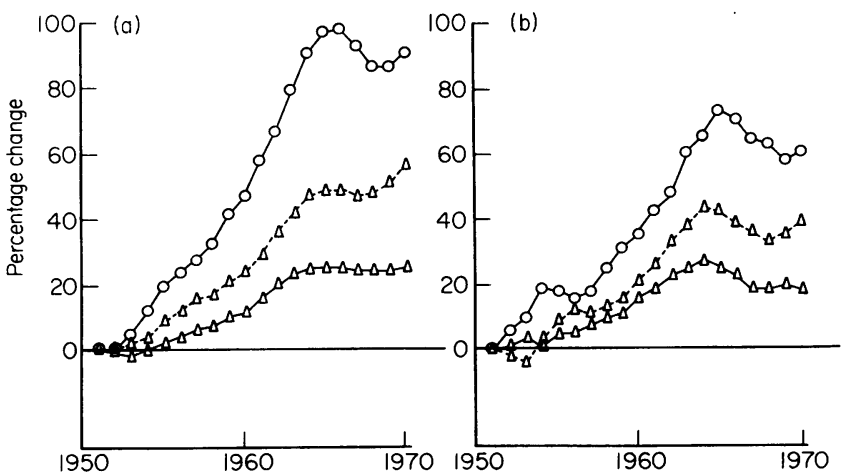

FIG. 3. Percentage change in death rates of males from ischaemic heart disease in three age groups $(O-O, 35-44$ years; $\triangle--\triangle$, 45-54 years; $\triangle-\triangle$, 55-64 years) in England and Wales (a) and Scotland (b). (Mean rate/100,000, 1950-52: England and Wales, $35-44,33 \cdot 3$; 45-54, 167.3; 55-64, 598.6; Scotland, 35-44, 53.0; $45-54,247 \cdot 7$; 55-64, 754.7 (DHSS, 1974).) 
make any important change in the mortality statistics. Halving the present time taken from onset to coming under care would anticipate but not necessarily prevent only an additional $5 \%$ of all deaths. It would thus appear logical and possibly imperative, that we at least try to prevent what we cannot cure.

\section{Primary prevention trials}

Some of the major trials designed to prevent coronary heart disease will now be described and their findings reviewed. They all have had serious criticism directed against them; what remains remarkable is that despite their limitations they all provide evidence which points in the same positive and possibly encouraging direction.

New York anti-coronary club (Christakis et al., 1966; Rinzler, 1968)

This study started in 1957, and enrolled in its experimental group 941 free living men aged 40-59 years and free of clinical coronary heart disease. Two years later, in 1959, a comparison group of 457 men was recruited. The study dealt primarily with alterations in nutritional habits (reduction of fat calories to $30-33 \%$ and substituting polyunsaturated for saturated fatty acids) and aimed at reducing blood cholesterol and also reducing weight in those volunteers who were obese. The results at 10 and 12 years are shown in Table 1, presented on a personyear basis for those who were actively involved covering the period of their active involvement, separately for those who lapsed into inactivity, and also for the comparison group. Criticisms of this study include the fact that control subjects were not selected from the same population as the test subjects or at the same time and that there is no information regarding other changes (e.g. exercise) which these 'coronary conscious' volunteers might have made.

TABlE 1. New York anti-coronary club. Incidence rates per 1,000 person-years in males aged 40-59 years at entry

\begin{tabular}{lccc}
\hline & \multicolumn{2}{c}{ Experimental (1957) } & 'Control' \\
\cline { 2 - 3 } & Active & Inactive & $(1959)$ \\
\hline Number & 941 & $(532)$ & 457 \\
1967 & & & \\
$\quad$ New events & 17 & 24 & 32 \\
$\quad$ Incidence & $4 \cdot 3$ & $7 \cdot 5$ & $10 \cdot 3$ \\
1969 & & & \\
$\quad$ New events & 37 & 42 & 51 \\
Incidence & 6.8 & 7.8 & $13 \cdot 4$ \\
\hline
\end{tabular}

Los Angeles veterans administration study (Dayton et al., 1969)

This is probably the best study so far in the whole difficult field of diet and blood cholesterol but it is a mixed primary and secondary prevention study; 846 men aged over 55 years (average age 65 years) living in an institution (Table 2). The groups were properly randomized, ate in different canteens and were to $c$. some extent supervised. The experimental group was $\vec{F}$ given a diet rich in polyunsaturated fatty acids and $\stackrel{?}{\rightarrow}$ the control group the ordinary American diet. The results were encouraging if not conclusive; sixty coronary events in the diet group and seventy-eight in the control group (not statistically significant). $\stackrel{\mathbb{2}}{2}$ Inclusion of cerebral infarction and other endpoints produced a result significant at the $1 \%$ level, but it is $\vec{\circ}$ a matter of opinion as to whether these groups should be included.

TABLE 2. Los Angeles veterans administration study 1959-1967. Number of fatal and non-fatal events in male veterans aged $54-88$ years

\begin{tabular}{lrcc}
\hline & Experimental & Control \\
\hline Number of subjects & 424 & & 422 \\
Myocardial infarction & 42 & 51 \\
Sudden death & 18 & & 27 \\
Cerebrovascular & 13 & & 25 \\
Other & 12 & & 16 \\
\hline \multicolumn{1}{c}{ Total } & 85 & $* *$ & 119 \\
\hline$\quad$ Fatal & 48 & $*$ & 70 \\
$\quad$ Non-fatal & 37 & n.s. & 49 \\
\hline
\end{tabular}

* $P<0.05 ;{ }^{* *} P<0.01 ;$ n.s. $=$ not significant.

This study was conducted in a particularly elderly group. Although most of the differences between the two groups in the study occurred under the age of 65 years, the numbers at these younger ages were not large enough to provide significant results. Another disadvantage was that the subjects were institutionalized and so we learn little or nothing about the practicality and adherence to such a regime of freeliving men. The inclusion of subjects with previous myocardial infarction or angina pectoris also makes the result difficult to evaluate.

The Finnish mental hospitals study (Miettinen et al., 1972)

This well known trial is also of considerable inte- 옥 rest and again is both primary and secondary (Table $\supset$ $3)$. It is very difficult to determine from the data

TABLE 3. Finnish mental hospital study (19591971). Age-adjusted death rates per 1,000 personyears in men and women aged 34-64 years

\begin{tabular}{lrc}
\hline & CHD & All causes \\
\hline Men & & \\
$\quad$ Both hospitals (diet) & $6 \cdot 61$ & $34 \cdot 84$ \\
$\quad$ Both hospitals (control) & $14 \cdot 08$ & $39 \cdot 50$ \\
Women & & \\
$\quad$ Both hospitals (diet) & $5 \cdot 21$ & $30 \cdot 87$ \\
$\quad$ Both hospitals (control) & $7 \cdot 90$ & $29 \cdot 01$ \\
\hline
\end{tabular}
政 
provided how many already had coronary heart disease. The study was started in 1958 in two mental hospitals in Helsinki and the mean age of the subjects was 51 years. One hospital put all of its patients on the test diet and those in the other hospital were observed but the diet was not changed. The diet used was one proportionately high in polyunsaturated fats but with no great reduction in total fat content. These regimes were maintained for 6 years and then reversed so that the hospital having the control diet went on to the test diet and vice versa for a further 6 years. There was a significant reduction in male mortality for the two periods on test diet compared with the two periods on the control diet. There was a much smaller and nonsignificant change in the females.

This is an encouraging result but there are major weaknesses in the study. The individuals were not the same throughout the 12 years and it is not clear from the report how many of the patients concerned had been a long time on the diet and how many only a short time. The population was a captive and unusual one and there was no randomization or blindness except in the classification of the results.

These three trials, the Anti-Coronary Club, the Los Angeles VA Study and the Finnish Mental Hospital Study, represent the best we have to offer in the way of primary prevention trials. The first is basically uncontrolled, the second and third are mixed primary and secondary and, although the results are encouraging, in none of them is there an absolutely convincing result.

\section{Chicago Coronary Prevention Evaluation Programme (Stamler, 1971)}

A somewhat different approach is that which aims at high-risk subjects only and is multifactorial in its modification programme (Table 4). The Chicago study involved 519 high risk male volunteers, aged 40-59 years, who were initially free of clinical CHD. The definition of high risk included various combinations of hypercholesterolaemia, hypertension, cigarette smoking, overweight and fixed minor Twave abnormalities. The programme undertook to correct treatable risk factors when present. The comparison group was derived from the National

TABle 4. Chicago Coronary Prevention Evaluation Programme. Seven-year mortality rates per 1,000 on multifactorial intervention in high-risk men aged 40-59 years

\begin{tabular}{lrrrr}
\hline & \multirow{2}{*}{$\begin{array}{c}\text { U.S.A. } \\
\text { pooling } \\
\text { project }\end{array}$} & \multicolumn{3}{c}{ Chicago Coronary PEP } \\
\cline { 3 - 5 } & 2916 & 377 & 519 & 141 \\
\hline Number & 15 & 2 & 4 & 10 \\
Sudden death & 20 & 5 & 12 & 27 \\
CHD mortality & 50 & 27 & 30 & 36 \\
\hline
\end{tabular}

Co-operative Pooling Project and subjects were matched for age and medical and risk factor findings; 2916 comparison subjects were selected.

The results were very impressive but the usual criticisms are directed against this study; it has no proper control group and it is concerned with a volunteer group of 'coronary conscious' subjects. Nevertheless, the results are quite striking.

\section{Cancer, gall-bladder disease and PUFA}

The possibility that the increased level of polyunsaturated fatty acids (PUFA) in the diet could lead to an increased incidence of cancer was raised by the Los Angeles VA study (Pearce and Dayton, 1971). Comparison of the cancer incidence in four other clinical trials of blood cholesterol lowering diets did not support this finding and the combined results of the five studies were consistent with the hypothesis that the diets do not influence cancer risk (Ederer et al., 1971; Heady, 1974).

The VA study also indicated an increased incidence of gall-stones in patients on the PUFA diets, but the Finnish mental hospital study did not show any such effect.

\section{Comment on primary prevention}

The gain in knowledge for the vast amount of work expended is not very impressive and one must reluctantly agree with those who point out that the sounder the methodology and the harder the endpoints, the less conclusive are the results.

While none of the reported trials is free from one or other important deficiency, the overall effect of the results does permit a conclusion that dietary manipulations in middle-aged or elderly men may lower the incidence of CHD, and that multifactorial intervention may produce a greater reduction in CHD mortality.

There is at present in progress a WHO-sponsored multifactorial primary prevention study with participating groups from Belgium, Italy, Poland and the U.K. (WHO European Collaborative Group, 1974). The recommendations include a diet for lowering blood cholesterol, stopping of cigarette smoking, weight reduction, treatment of hypertension and daily physical exercise. Bearing in mind the vicissitudes and criticisms of all previous studies, the collaborators may be excused their hope that, 'if fortune favours us, we may finish up with a firm conclusion'.

\section{Secondary prevention}

Over the past 10 years there have been a number of studies designed to prevent death or recurrent myocardial infarction in patients already known to have coronary heart disease. The earlier studies were based on the lowering of blood cholesterol by 
dietary means and the results were an unhappy mixture of encouragement and disappointment (Research Committee, 1965; Rose, Thomson and Williams, 1965; Leren, 1970; MRC Research Committee, 1968; Bierenbaum, 1973). More recently, drugs have been used, mainly for their effects on blood lipids, and again the results have been confusing. Studies of clofibrate in secondary prevention in Britain gave results which have been of little practical help to the physician (Physicians of Newcastle, 1971; Scottish Society of Physicians, 1971). Recently, the results of a major American trial of clofibrate and nicotinic acid in secondary prevention have allowed more definite conclusions to be drawn about the use of these two drugs (Coronary Drug Project Research Group, 1975). In summary, neither drug produced any significant improvement in total mortality or coronary heart disease mortality and both drugs were associated with an increased incidence of several cardiovascular events.

The American Coronary Drug Project also showed that the 5-year incidence of gall-stones was 3\% in myocardial infarction patients treated with clofibrate compared with $1.3 \%$ in the control group. It is known that clofibrate increases the excretion of cholesterol through the biliary tract (Grundy et al., 1972) and increases the lithogenicity of bile (Pertsemlidis, Panveliwalla and Ahrens, 1974) so that this result is not altogether surprising. Data from the international trial of the primary prevention of IHD using clofibrate (Heady, 1973) also show an increased incidence of cholecystectomy for gall-stones in the clofibrate group, but the 5-year rate is only $1 \%$ (Cooper, Geizeroza and Oliver, 1975).

\section{Aspirin and coronary heart disease}

The results of a randomized controlled trial of a single daily dose of aspirin in the prevention of reinfarction in Wales and England were inconclusive (Elwood et al., 1974). In three centres mortality was higher in the placebo group and in two centres it was higher in the aspirin group. The differences between the death rate curves were small but the death rate in the placebo group was always higher than in the aspirin group. On the other hand, the results of two large independent studies in the United States were consistent with the hypothesis that aspirin does protect against recurrence of CHD events (Boston Collaborative Drug Surveillance Group, 1974). More recently a prospective study in the U.S.A. of over 1 million men and women has shown that CHD death rates were no lower among people who took aspirin often than among those who did not do so (Hammond and Garfinkel, 1975). Aspirin will almost certainly attract more interest and further studies but there is at present no strong support for its general use in secondary prevention.
Arising from the aspirin studies and from a general concern regarding clinical trials, there is one note- $z$ worthy aspect of the American Coronary Drug $\stackrel{\mathbb{Q}}{\mathcal{Q}}$ Project report. Fifty-three clinics took part and in $C$. twenty-nine the mortality on clofibrate was higher $\vec{F}$ than the placebo mortality; in twenty-four clinics the clofibrate mortality was less than the placebo mortality. A similar pattern was seen with nicotinic $\frac{\overline{\bar{N}}}{\bar{\rho}}$ acid. The critical need for replication in trials, $\frac{\widehat{D}}{\Phi}$ however well controlled and randomized, is obvious. $\unrhd$

\section{Comment on secondary prevention}

There is good evidence that the risk of recurrence of a CHD event cannot usefully be assessed by the $\vec{\omega}$ usual CHD risk factors. At least in the early years $\frac{\text { o }}{\circ}$ after recovery from a major episode of CHD, othero clinical and electrocardiographic characteristics are much more reliable indicators of the prognosis o (Norris et al., 1973; Vedin, Wilhelmsson and Werko, 8 1975; Mulcahy et al., 1975). However, plasma lipids, cigarette smoking and physical inactivity continue to make some contribution to the assessment of prognosis (Coronary Drug Project Research Group, 1974). Mortality has been shown to be reduced in $\vec{c}$ patients who stop smoking after a CHD event (Wilhelmsson et al., 1975) and treatment with a betablocking agent (alprenolol) has also been shown reduce mortality after myocardial infarction, espe cially mortality from sudden death (Wilhelmsse. et al., 1974). Physical training programmes hat also been promoted and are a fairly expensive method of treatment with a high drop-out rate, and although the risk of serious complications is not $\stackrel{\mathbb{Q}}{\varrho}$ great they are not completely safe (Blackburn, 1974). Anyway, the secondary preventive effect is small; 3 far less than from stopping smoking or using a betablocking drug. In general, it would seem that active encouragement to return to work, advice to stop smoking, simple dietary recommendations to lower 3 blood lipids and reduce weight, control of high blood pressure and light unsupervised exercise are likely in combination to achieve the best results in secondary prevention.

\section{Conclusion}

It seems unlikely that the proof required to establish conclusively that a particular dietary regime is critical to the primary prevention of CHD will be provided in the foreseeable future. The present series of multifactorial trials may result in a reduction of coronary heart disease, but cannot indicate which of the many factors employed are of critical importance. However, let us not confuse our aims. On the one hand there is the search for a complete understanding of the aetiology and pathogenesis of the disease and on the other there is a need to apply what we already know to the prevention of the 
disease. The latter need not wait upon the former-it has rarely done so in the history of medicine. Continued research into the aetiology and pathogenesis of CHD is vital, but we know enough at present to make an attempt at least to prevent the disease which we know we cannot cure. Let this paper end with a quotation from Francis Bacon, who some 400 years ago provided a reasonable approach to the primary prevention of CHD: 'Examine thy customs of diet, sleep, exercise, apparel and the like; and try, if anything thou shalt find hurtful, to discontinue it by little and little; but so if thou dost find any inconvenience by the change, then come back to it again'.

\section{References}

Armstrong, A., Duncan, B., Oliver, M.F., Julian, D.G., Donald, K.W., Fulton, M., Lutz, W. \& Morrison, S.L. (1972) Natural history of acute coronary heart attack. A community study. British Heart Journal, 34, 67.

Bierenbaum, M.L., Fleischman, A.I., Raichelson, R.I., HAYTon, T. \& Watson, P.B. (1973) Ten-year experience of modified-fat diets on younger men with coronary heartdisease. Lancet, i, 1404.

Blackburn, H. (1974) Disadvantages of intensive exercise therapy after myocardial infarction. In: Controversy in Internal Medicine II (Ed. by F. J. Ingelfinger, A.S. Relman and M. Finland), p. 162. Philadelphia, W. B. Saunders.

Boston Collaborative Drug Surveillance Group (1974) Regular aspirin intake and acute myocardial infarction. British Medical Journal, 1, 440.

Christakis, G., Rinzler, S.H., Archer, M., Winslow, G., Jampel, S., Stephenson, J., Friedman, G., Fein, H., KRAUS, A. \& JAMES, G. (1966) The anti-coronary club. A dietary approach to the prevention of coronary heart disease-a 7-year report. American Journal of Public Health, 56, 299.

Cooper, J., Geizeroza, H. \& Oliver, M.F. (1975) Clofibrate and gallstones. Lancet, i, 1083.

Coronary Drug Project Research Group (1974) Factors influencing long term prognosis after recovery from myocardial infarction-three year findings of the Coronary Drug Project. Journal of Chronic Diseases, 27, 267.

Coronary Drug Project Research Group (1975) Clofibrate and niacin in coronary heart disease. Journal of the American Medical Association, 231, 360.

Dayton, S., Pearce, M.L., Hashimoto, S., Dixon, W.J. \& TomiYASU, U. (1969) A controlled clinical trial of a diet high in unsaturated fat in preventing complications of atherosclerosis. Circulation, 40 (Suppl. II).

Department of Health and Social Security (1974) Diet and coronary heart disease. Report on Health and Social Subjects No. 7. London, H.M. Stationery Office.

Ederer, F., Leren, P., Turpeinen, O. \& Frantz, I.D. (1971) Cancer among men on cholesterol-lowering diets. Experience from five clinical trials. Lancet, ii, 203.

Elwood, P.C., Cochrane, A.L., Burt, M.L., Sweetnam, P.M., Williams, G., Wilsby, E., Hughes, S.J. \& Renton, R. (1974) A randomised controlled trial of acetyl salicy lic acid in the secondary prevention of mortality from myocardial infarction. British Medical Journal, 1, 436.

Grundy, S.M., Ahrens, E.H., Salen, G., Schreibman, P.H. \& Nestel, P.J. (1972) Mechanism of action of clofibrate on cholesterol metabolism in patients with hyperlipidemia. Journal of Lipid Research, 13, 531 .
Hammond, E.C. \& Garfinkel, L. (1975) Aspirin and coronary heart disease. Findings of a prospective study. British Medical Journal, 1, 269.

Heady, J.A. (1973) A cooperative trial on the primary prevention of ischaemic heart disease using clofibrate: designs, methods and progress. Bulletin of the World Health Organization, No. 48, p. 243.

Heady, J.A. (1974) Are PUFA Harmful? British Medical Journal, 1, 1156.

KinLEN, L.J. (1969) A community study of acute myocardial infarction and sudden death. D.Phil. Thesis, Oxford.

LEREN, P. (1970) Oslo diet-heart study. 11-year report. Circulation, 42, 935.

MRC RESEARCH Committee (1968) Controlled trial of soya bean oil in myocardial infarction. Lancet, ii, 693.

Miettinen, M., Turpeinen, O., Karvonen, M.J., Elosuo, R. \& PaAvilainen, E. (1972) Effect of cholesterol-lowering diet on mortality from coronary heart disease and other causes. Lancet, ii, 835.

Mulcahy, R., Hickey, N., Graham, I. \& McKenzie, G. (1975) Factors influencing long-term prognosis in male patients surviving a first coronary attack. British Heart Journal, 37, 158.

Norris, R.M., Caughey, D.E., Deeming, L.W., Mercer, C.J. \& ScoTt, P.J. (1973) Prognosis following acute myocardial infarction. New Zealand Medical Journal, 12, 77.

Pearce, M.L. \& Dayton, S. (1971) Incidence of cancer in men on a diet high in polyunsaturated fat. Lancet, i, 464.

Pedoe, H.T. (1975) Myocardial infarction in East London. British Heart Journal, 37, 550.

Pertsemlidis, D., Panveliwalla, D. \& Ahrens, E.H. (1974) Effects of clofibrate and of an estrogen-progestin combination on fasting biliary lipids and cholic acid kinetics in man. Gastroenterology, 66, 565.

Physicians of the Newcastle upon Tyne Region (1971) Trial of clofibrate in the treatment of ischaemic heart disease. British Medical Journal, 4, 767.

Research Committee of Four London Hospitals (1965) Low-fat diet in myocardial infarction. Lancet, ii, 501.

RINZLER, S.H. (1968) Primary prevention of coronary heart disease by diet. Bulletin of the New York Academy of Medicine, 44, 936.

Rose, G.A., Thomson, W.B. \& Williams, R.T. (1965) Cornoil in treatment of ischaemic heart disease. British Medical Journal, 1, 1531.

Scottish Society of Physicians Research Committee (1971) Ischaemic heart disease. A secondary prevention trial using clofibrate. British Medical Journal, 4, 755.

StamLer, J. (1971) Acute myocardial infarction-progress in primary prevention. British Heart Journal, 33 (Suppl.), 145.

Vedin, A., Wilhelmsson, C. \& Werko, L. (1975) Chronic alprenolol treatment of patients with acute myocardial infarcation after discharge from hospital. Effects on mortality and morbidity. Acta medica scandinavica (Suppl.), 575.

Wilhelmsson, C., Vedin, J.A., Elmfeldt, D. \& WilhelmSEN, L. (1975) Smoking and myocardial infarction. Lancet, i, 415.

Wilhelmsson, C., Wilhelmsen, L., Vedin, A., Tibblin, G. \& WERKo, L. (1974) Reduction of sudden deaths after myocardial infarction by treatment with alprenolol. Lancet, ii, 1157.

WHO European Collaborative Group (1974) An international controlled trial in the multifactorial prevention of coronary heart disease. International Journal of Epidemiology, 3, 219. 